\title{
Designing Multi-User Virtual Environment (MUVE) for Learning English Using Virtual Reality Application: Case Study on Senior High School Students in Yogyakarta
}

\author{
Ozzi Suria \\ Information System \\ Department, Faculty of \\ Information Technology \\ Universitas Mercu Buana \\ Yogyakarta \\ Yogyakarta, Indonesia
}

\author{
Albert Yakobus Chandra \\ Information System \\ Department, Faculty of \\ Information Technology \\ Universitas Mercu Buana \\ Yogyakarta \\ Yogyakarta, Indonesia
}

\author{
Putri Taqwa Prasetyaningrum \\ Information System \\ Department, Faculty of \\ Information Technology \\ Universitas Mercu Buana \\ Yogyakarta \\ Yogyakarta, Indonesia
}

\begin{abstract}
The use of e-learning as online learning in educational institution can provide ease of access to learning materials for students. They can do online activities in virtual environment. Combined with immersive technology such as Virtual Reality (VR), the online learning experience can be enhanced. A Multi-User Virtual Environment (MUVE) using VR application can be used to create authentic and immersive learning experience. Based on students' interest and teachers' opinion in previous surveys, this study proposes a design of MUVE using VR application for learning English. The detail of design will be explained using three approaches i.e. architecture diagram, use-case diagram, and interaction model flowchart. Although there are limitations in this proposed design, the main functionalities and interaction models are well-defined in this study.
\end{abstract}

Keywords: multi user virtual environment, virtual reality, learning in MUVE, English learning using VR

\section{INTRODUCTION}

Technology has been used in many ways to help students and teachers' activities in the classroom. For example, the use of e-learning as online learning in educational institution which provide virtual environment for students to access materials, collaborate, and discuss [1]-[3]. The immersive technologies such as Augmented Reality (AR), Virtual Reality (VR), and Mixed Reality (MX) are also used to help teachers to explain learning materials with visually attractive models [4]-[6]. By using these technologies, a good learning experience can be achieved.

Previous studies on VR technology stated that learning using VR can enhance learning activities and learning experience [7][8]. Students can obtain immersive learning experience and actively participate in teaching and learning activities [9], [10]. By using VR as an immersive technology and the nature of e-learning as online media, this study tries to design a Multi-User Virtual Environment (MUVE) to learn English using VR application.

In the previous research, two surveys have been conducted to get information about students' interest on learning English using VR in a Senior High School (SHS), Yogyakarta and to get teachers opinion on using VR as supporting tools in their class. From 100 students who filled the questionnaire, about $80.8 \%$ students are interested to learn English using VR. They also feel that VR helped and motivated them to learn. This result is supported by the teachers' opinion that $100 \%$ of 45 teachers believed that VR can be used as supporting tools to help them to teach in the class. Based on these result this study tries to propose a design of MUVE using VR application to learn English.

\section{RESEARCH FOCUS}

This study tries to propose an architectural design of MUVE for learning English using VR application. The design will be focused on the important functionalities of VR application and the interaction model between students and teacher.

\section{METHOD}

The application design is created to understand the requirement specification of MUVE using VR application and the interaction models. In this study, the design process is conducted in three approaches i.e. designing the architecture diagram, mapping users' action and application functionalities, and determining interaction model between users. The architecture diagram presents elements and their relations to serve users' request from the application. Additionally, the details about handling application request and synchronizing data are also discussed.

The users' action and application functionalities are described using use-case diagram. The added value of using use-case diagram is that it can be used to analyze the system requirement and identify its important functionalities [11], [12][13]. This approach is used to specify actions that might be done by each user, especially students and teachers. Each defined use case is based on interaction models which were described using flowchart. There are two interaction models proposed in this design i.e. learning model and test model. The design is focused on these interaction models.

\section{DISCUSSION}

This section discussed the details of each approach used in design process. 


\subsection{Architecture Diagram}

The architecture diagram is a graphical representation to describe components and the relation between components that are used by the application to handle users' request. The diagram is displayed in figure 1 .

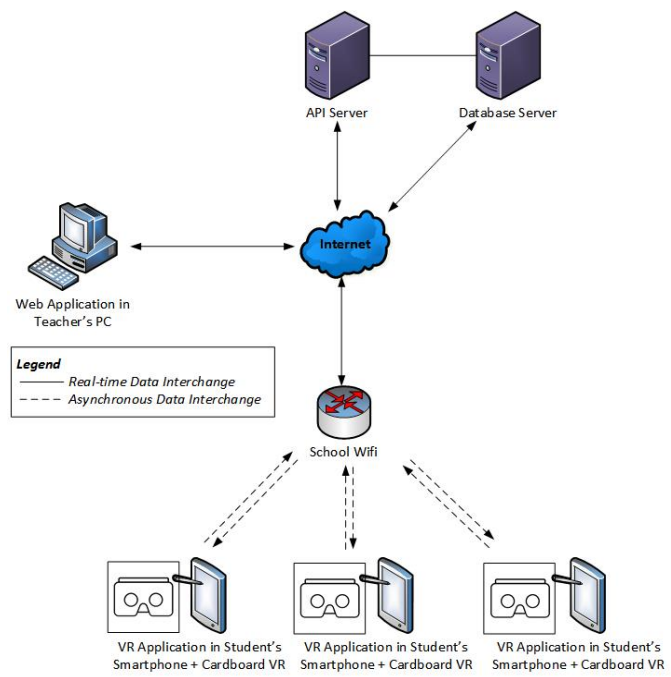

Figure. 1 Example of an image with acceptable resolution

Based on figure 1 there are two applications that might be required to create MUVE using VR and also manage the users' data by online i.e. the VR mobile application and data web portal.

1) VR Mobile Application: The VR mobile application is an application designed to run in the students' mobile device to learn English and also do the test. To display the VR content correctly, the students are required to use cardboard VR with their mobile devices. All multimedia elements such as text, image, video, 360 video are supported. The application offers functionalities that can be used online or offline. For example, the students can learn learning materials and do the individual exercise offline. After having finished, they can sync their progress to the application server. Online activities, such as group test, can be done in classroom. Teachers can guide students to join a specific class and do the prepared test. The question type may be in the form of multiple choice or fill in the blank. As stated in previous research [14], this online activities might required an internet connection to create good learning experience.

2) Data Web Portal: The web portal is an application used to manage all data used in VR application. Teachers can use it to manage the lesson materials, update their question bank, prepare the test, and view the students activity. Unlike the VR mobile application, this application does not need to be synced. The user can open it through desktop browser or mobile browser.

The API server in figure 1 is used to bridge data interchange between application database, the VR mobile application, and also external applications used by school. For example, if the school has teacher portal to submit lesson grades and record students' attendance, the students' grade from this application can be synced to that portal.

\subsection{Use Case Diagram}

In this proposed design, the use case diagram is focused on student and teacher's action. The use case diagram is displayed in figure 2 .

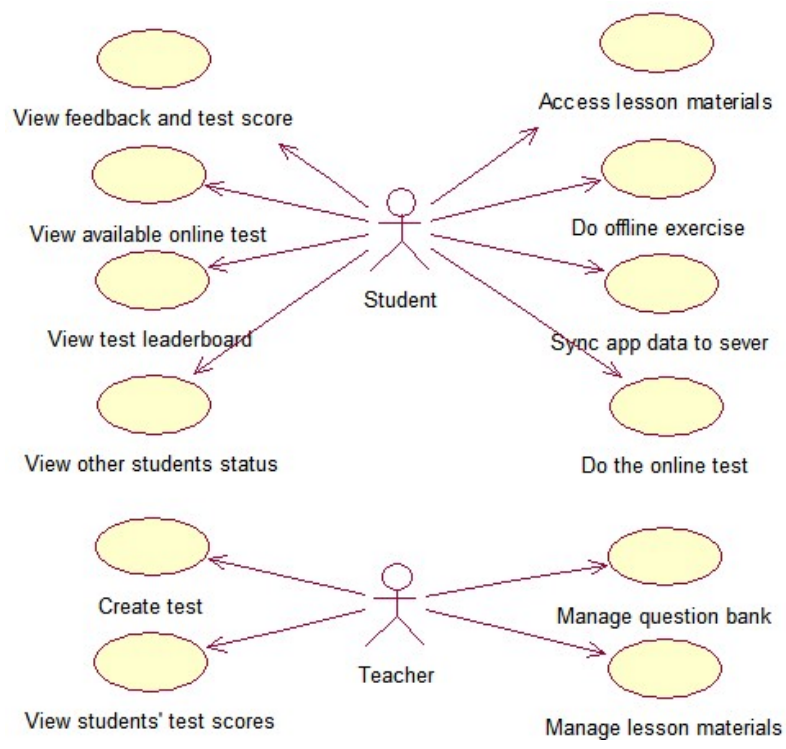

Figure. 2 The use case diagram

As displayed in figure 2, the student and the teacher have different actions in accordance with their role. The teacher can manage lesson materials, submit test question in question bank, prepare the test, and also views students' test score. On the other hand, the student can access the lesson materials, do offline exercise, view available online test created by the teacher, do online test, view feedback and test score, view test leaderboard, and also view other students' status. However, the interaction between student and teacher is still limited. Although the students can do the test simultaneously, they cannot communicate with the teacher directly using the VR application.

\subsection{Interaction Models}

As mentioned earlier in methods, there are two interaction models used in this design i.e. students learn and practice English by themselves using VR application and students do the test together with other students using VR application. The interaction model of self-learning is shown in figure 3 whereas the interaction model of group-learning is shown in figure 4.

The self-learning model in figure 3 describes the learning interaction between a student and a teacher. A student can learn and do exercise using VR application by himself as long as he wants or as approved by the teacher. However, he cannot ask the teacher directly from application. The communication between the student and the teacher is limited in this model.

The group-learning model in figure 4 describes the learning interaction among students and between students and a teacher. The interaction among students are created after the students have entered the test room. The students can see other students' progress during the test. However, they cannot communicate through the application. This is also applied to the interaction between the students and the teacher. Although 
the teacher can see the students' progress, the teacher cannot interact with them through the application. But, since this model is used in the class activity, they still can communicate to each other directly.

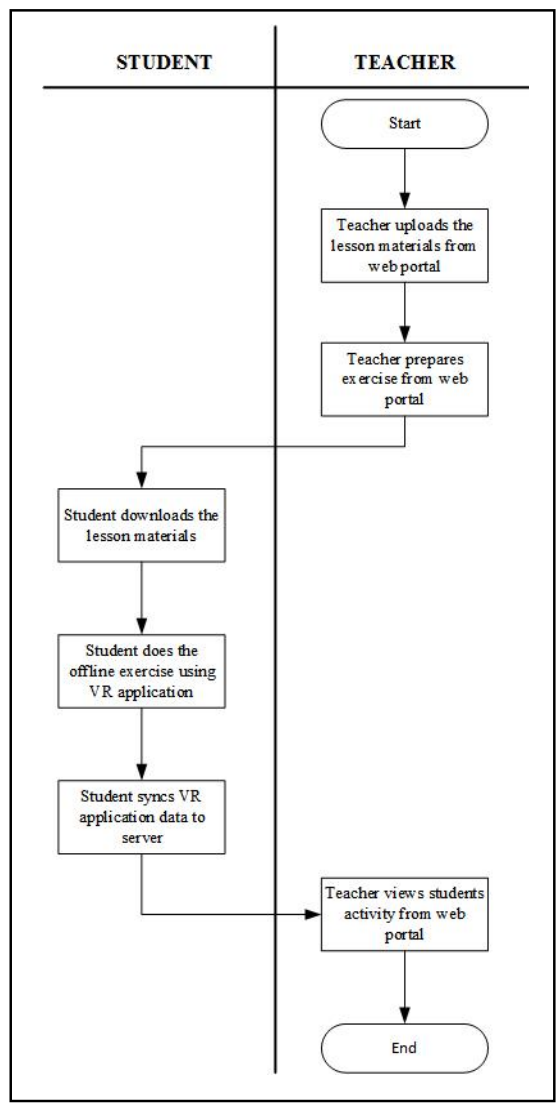

Figure. 3 The interaction model of self-learning

\section{CONCLUSIONS}

In summary, MUVE using virtual reality is possible to be implemented using the proposed design. However, the interaction among students and also between students and teacher are still limited in this design. In future research, a prototype application of this design might be required to simulate the designed functionalities and also to measure the application performance in mobile device. The VR mobile application will be installed in students' device. Therefore, it is recommended to test the application performance in several mobile devices due to the hardware specification differences in every device.

\section{ACKNOWLEDGMENTS}

This research was fully supported by Kementrian Riset dan Teknologi Pendidikan Tinggi (KEMENRISTEKDIKTI) Republik Indonesia (based on decree No. 7/E/KPT/2019 19 Februari 2019 and agreement No. 227/SP2H/LT/DRPM/2019 11 Maret 2019, No. B/1436.11/L5/RA.00/2019 15 April 2019, and No. 184/LPPM/UMBY/IV/2019. This collaboration research is conducted between Universitas Mercu Buana Yogyakarta and Universitas Gadjah Mada. We would like to express our gratitude to Ir. Paulus Insap Santosa M.Sc., Ph.D and Ir. Lukito Edi Nugroho M.Sc., Ph.D who provided great advice and assistance in developing research methods and data analysis in this work.

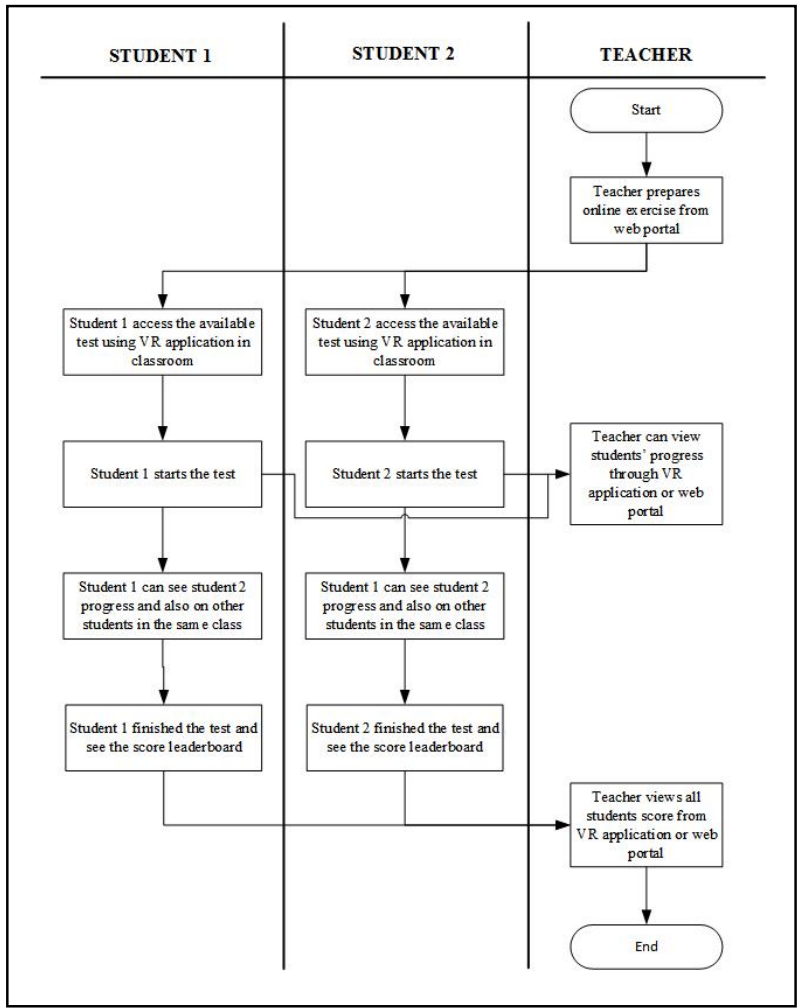

\section{REFERENCES}

[1] W. M. Al-Rahmi et al., "Integrating Technology Acceptance Model with Innovation Diffusion Theory: An Empirical Investigation on Students' Intention to Use E-Learning Systems," IEEE Access, vol. 7, pp. 26797-26809, 2019, doi: 10.1109/ACCESS.2019.2899368.

[2] W. M. Al-Rahmi et al., "Use of E-Learning by University Students in Malaysian Higher Educational Institutions: A Case in Universiti Teknologi Malaysia," IEEE Access, vol. 6, pp. 14268-14276, 2018, doi: 10.1109/ACCESS.2018.2802325.

[3] S. A. Salloum, A. Qasim Mohammad Alhamad, M. Al-Emran, A. Abdel Monem, and K. Shaalan, "Exploring Students' Acceptance of E-Learning Through the Development of a Comprehensive Technology Acceptance Model," IEEE Access, vol. 7, pp. 128445-128462, 2019, doi: 10.1109/access.2019.2939467.

[4] M. E. C. Santos, A. Chen, T. Taketomi, G. Yamamoto, J. Miyazaki, and H. Kato, "Augmented reality learning experiences: Survey of prototype design and evaluation," IEEE Trans. Learn. Technol., vol. 7, no. 1, pp. 38-56, 2014, doi: 
10.1109/TLT.2013.37.

[5] S. Kang and S. Kang, "The Study on The Application of Virtual Reality in Adapted Physical education," Cluster Comput., vol. 4, pp. 1-5, 2018, doi: 10.1007/s10586-018-2254-4.

[6] J. A. Frank and V. Kapila, "Mixed-reality learning environments: Integrating mobile interfaces with laboratory test-beds," Comput. Educ., vol. 110, pp. 88-104, 2017, doi: 10.1016/j.compedu.2017.02.009.

[7] W. Liou and C. Chang, "Virtual Reality Classroom Applied to Science Education," pp. 1-4, 2018.

[8] F. Yang and W. Wu, "The Application of Virtual Reality in E-Learning," 2010 Int. Conf. E-bus. EGovernment, pp. 5548-5551, 2010, doi: 10.1109/ICEE.2010.1389.

[9] J. Martín-Gutiérrez, C. E. Mora, B. Añorbe-Díaz, and A. González-Marrero, "Virtual Technologies Trends in Education," Eurasia J. Math. Sci. Technol. Educ., vol. 13, no. 2, pp. 469-486, 2017, doi: 10.12973/eurasia.2017.00626a.

[10] E. $\mathrm{Hu} \mathrm{Au}$ and J. J. Lee, "Virtual Reality in
Education: a Tool for Learning in The Experience Age," Int. J. Innov. Educ., vol. 4, no. 4, p. 215, 2018, doi: 10.1504/ijiie.2017.10012691.

[11] N. Thompson and D. Toohey, "Teaching Case Analysis of an Electronic Voting System," J. Inf. Syst. Educ., vol. 25, no. 1, pp. 13-22, 2014.

[12] O. Suria, "Development of Word Game Algorithm for Learning Javanese Script," CommIT (Communication Inf. Technol. J., vol. 12, no. 2, p. 73, 2018, doi: 10.21512/commit.v12i2.4792.

[13] J. M. Almendros-Jiménez and L. Iribarne, "Describing use-case relationships with sequence diagrams," Comput. J., vol. 50, no. 1, pp. 116-128, 2007, doi: 10.1093/comjnl/bx1053.

[14] Y. P. Duan, H. T. Fu, and L. Zhu, "Application of virtual reality technology in agriculture," Appl. Mech. Mater., vol. 687-691, pp. 2391-2394, 2014, doi: $\quad 10.4028 /$ www.scientific.net/AMM.687691.2391 